\title{
This is my vision': How students depict critiques along with themselves during critiques
}

Jason K. McDonald

Brigham Young University, jason_mcdonald@byu.edu

Esther Michela

University of Tennessee, Knoxville

Follow this and additional works at: https://scholarsarchive.byu.edu/facpub

Part of the Instructional Media Design Commons

\section{Original Publication Citation}

McDonald, J. K., \& Michela, E. (2020). 'This is my vision': How students depict critiques along with themselves during critiques. Journal of Design Research, 18(1/2), 57-79. https://doi.org/ 10.1504/JDR.2020.10033227

\section{BYU ScholarsArchive Citation}

McDonald, Jason K. and Michela, Esther, "This is my vision': How students depict critiques along with themselves during critiques" (2020). Faculty Publications. 4480.

https://scholarsarchive.byu.edu/facpub/4480 accepted for inclusion in Faculty Publications by an authorized administrator of BYU ScholarsArchive. For more information, please contact ellen_amatangelo@byu.edu. 
“This is My Vision”: How Students Depict Critiques Along with Themselves During Critiques

\author{
Jason K. McDonald \\ Brigham Young University \\ Esther Michela \\ University of Tennessee, Knoxville
}

Corresponding author:

Jason K. McDonald

Esther Michela

150-E MCKB

Provo, UT 84602

(801) 422-3674

535 Bailey Education Complex

1122 Volunteer Blvd.

Knoxville, TN 37996

jason@byu.edu

esther.michela@gmail.com

\title{
Conflict of interest
}

Jason K. McDonald is employed by Brigham Young University, the university under study.

Esther Michela was a student at Brigham Young University, the university under study, at the time this study was conducted. 


\begin{abstract}
In this article we consider critiques within the design studio as how students press forward into possible forms of the self that are opened up through studio participation. We contrast this with a view of critiques as primarily being a pedagogical or socializing technique under the control of instructors and other critics. We carried out our inquiry using interviews with six studio students, studying how they depict critiques and how they depict themselves when being critiqued. Students' depictions of critiques included their being (a) signal in the noise; (b) windows into their critics' character; and (c) a type of text to be interpreted. Their depictions of themselves included being (a) clear-sighted; (b) street-smart; and (c) creative. We conclude by discussing what these depictions might mean about how instructors/critics can frame critiques in ways that facilitate students using them to take up possibilities that are opened up through studio participation.
\end{abstract}

Keywords: design critique; design education; design studio; qualitative research; philosophy of design 
Our purpose in this article is to consider an alternative way of understanding critiques within design studio pedagogy. Rather than viewing them as primarily meant to achieve educational outcomes such as constructing design knowledge (Cennamo \& Brandt, 2012), or to socialize students into becoming members of a profession (Scagnetti, 2017), we frame critiques as how students press forward into possible forms of the self that are opened up through studio participation (Dreyfus, 1991; Yanchar, 2016). In this view, the pedagogical and socializing affordances of critiques are still important, but less-so in the sense of enabling instructors (or other critics) to manage students' education, and more because they allow students, themselves, to take up specific ways of life that are made available through studio participation.

We develop our account based on the voices of studio students themselves. In a series of interviews we carried out with students from a variety of studios we heard accounts that illustrate how they take stands on various choices presented to them as they participated in critiques. In our interview analysis we attempted to clarify what these accounts say about the ways students use critiques to strive towards some sense of personal becoming, even when that becoming is clearly pulled on by other social forces. Our goal was to synthesize what students told us into a report that "points out hitherto unnoticed aspects" (Packer, 2018, p. 482) of critiques that are not always visible from a perspective that frames them as a tool for managing student development. The specific questions guiding our research were: (a) how do students depict critiques they experience? (b) how do students depict themselves when they experience critiques? and (c) what do these depictions reveal about how students use critiques to press forward into possible forms of the self that are opened up through the studio?

Our interest in this issue lies in our agreement with other scholars that processes of critique - especially in high stakes forms — can have a detrimental effect on students' well-being, 
and so should be improved to better promote healthier studio cultures (Anthony, 1991; Gray \& Smith, 2016; Koch, Schwennsen, Dutton, \& Smith, 2002; Percy, 2004). While we recognize the perspectives our research participants provided are not universal for every student, we contend they are a realistic portrayal of what studio critiques can be and become. So we offer them as an alternative to what we will show to be a common attitude that, however well-meaning it might be, seems to consider the critique to be an object that acts upon students, instead of how they engage in what Packer (2018) called their own "projects of self-management" (p. 451). And, as we will ultimately conclude, by studying students' depictions, instructors and critics can better understand their own experiences as those who offer critiques. This, in turn, can help them better cooperate with students as those students press into the possibilities that studio life affords.

\section{Literature Review}

In design education the term critique is flexible. It is used to describe a range of activities where students receive feedback on their work (Hokanson, 2012), including formal jury evaluations (Anthony, 1991), in-class discussions between instructors and students (Oh, Ishizaki, Gross, \& Do, 2013), or informal, out-of-class help students give each other on their own (Gray, 2013b). Likewise, the critique's purpose has also been considered broadly. Some research emphasizes its pedagogical role, where the critique is a coaching technique to help students develop the knowledge, practices, and habits associated with a discipline (Oh et al., 2013; Schrand \& Eliason, 2012; Uluoğlu, 2000). Another theme, originating in scholarship on design as a process of identity formation (Lawson \& Dorst, 2009; Nelson \& Stolterman, 2012; Tracey \& Hutchinson, 2016), is the critique's socializing effects, meaning how it initiates students into becoming legitimate members of a profession (Brandt et al., 2013; Dannels, Gaffney, \& Martin, 2008; Scagnetti, 2017). Critical perspectives, on the other hand, tend to highlight how critiques 
(especially in high-stakes forms) can have a detrimental effect on students' well-being (Anthony, 1991; Gray \& Smith, 2016; Ledewitz, 1985), sometimes even becoming so adverse as to be "largely antithetical to ... reflective learning" (Webster, 2006, p. 17). This is consistent with critical perspectives on studio pedagogy in general, highlighting its potential to reinforce harmful patterns of domination and oppression, both cultural and political (Crysler, 1995; Dutton, 1991; Willenbrock, 1991)

Yet regardless of the perspective taken, positive or negative, the role critiques play in the studio is viewed as significant, having been called by Gray (2013a) "the centre of design practice ... in the education of a designer" (p. 110), and by Cossentino (2002) as "the heart of the design process" (p. 43). It is in how scholars address this acknowledged significance that we find the issue that frames our research: do critiques contain within themselves some educational and socializing power that brings about the outcomes of studio pedagogy? or are they a way that students press forward into possible forms of the self that are opened up through studio participation? Scholarship often describes critiques (as well as other studio activities) in ways that highlight how they can be "scaffolds" for students' agency, "providing the necessary concepts and metacognitive space [for them] to build [an] identity" they are drawn towards (Gray, 2014, p. 262). Such scaffolds include encouraging students to reflect on their own practice (Cardella, Buzzanell, Cummings, Tolbert, \& Zoltowski, 2014; Dannels \& Martin, 2008), providing models of how professional design is conducted (Budge, 2016), and adopting patterns of language or comportment that cue students about how they should interact with others (Brandt et al., 2013; Morton \& O’Brien, 2005; Oak \& Lloyd, 2016).

At the same time, however, the language researchers use can also suggest that critiques are deterministic, meaning the affordances of critiques are somehow causal forces that produce 
certain outcomes. We note this in language that describes how critiques "stimulate" students' reflection (Cennamo \& Brandt, 2012, p. 842), how design knowledge is “embedded" into students through critiques (Oak, 2000, p. 92), or in references to how critiques (along with other aspects of the studio) are a mechanism for "transferring a specific identity to . . practitioners" (Schrand \& Eliason, 2012, p. 51; for other examples see Oh et al. [2013] and Uluoğlu [2000]). While we do not claim these scholars were intentionally describing critiques as causal forces, such language reflects a pervasive assumption in the social sciences that human beings are organisms shaped by environmental pressures - an assumption that researchers have found very difficult to dislodge (for reviews, see Rychlak, 1991; Slife \& Williams, 1995; Williams, 1987). And educational researchers have argued that even when this language is used inadvertently, it can limit the imaginations of those adopting pedagogical strategies, narrowing their view of what is possible in their relations with students (McDonald \& Gibbons, 2009; Nixon, 2017; Osguthorpe \& Osguthorpe, 2007). It can also encourage a stance of "manipulation and control" (Matthews \& Yanchar, 2018, p. 152), where educators see students as objects they must manage so that their (the educators') desired outcomes are achieved, rather than cooperating with students in caring relationships that support students' achievements (see also Gur \& Wiley, 2007). Both of these points are consistent with Belluigi’s (2016) observation that certain "constructions of the student-supervisor relationships $[\mathrm{sic}]$ in ... [the studio] are seemingly in conflict with [a] sense of partnership and student autonomy" (p. 23). We do not deny that social factors like critiques are powerful forces that can have an influence on what students become. But, as many scholars have argued, views of people as being controlled by social forces cannot account for what they actually achieve in the complex realms of practical activity (Dreyfus, 2017; Guignon, 2012; Patton, 1989; Yanchar, Spackman, \& Faulconer, 2013). 
At the same time, however, recognizing that people are not controlled by social forces does not require that one view them as intentionally building their identities like they might build a physical structure like a house. This would imply they make choices in the sense of actively deliberating between options, or calculating the costs and benefits of possible alternatives, in order to purposefully move towards an end (like a certain identity) they understand in advance. But this is not usually what happens. Rather, people make choices for a number of reasons, sometimes purposeful, other times for reasons they cannot articulate, but often based on what has worked in the past, without a sense of purpose or goal in mind (Dreyfus, 2014). As people negotiate the possibilities the world makes available to them-even if they do not have a specific aim — over time their patterns of negotiation will sum up to a definable identity. As Polt (1999) described it:

At every moment, I am following one possibility rather than a host of others - for instance, I go to the university today and teach my class, rather than joining the Army or shoplifting. ... As I go on living, I build an identity. I become myself; I define myself as a professor, rather than as a soldier or criminal. . . . [and when] I have to take a stance on who I am ... I do so by acting as a professor. (pp. 34-35)

So rather than circumstances controlling what a person becomes, it is more accurate to view them as the settings in which that individual is "enable[d] . . to act as a self-reflective agent" (Sugarman, 2005, p. 805), conducting herself in a manner consistent with the way she has interpreted herself over time.

In summary, we argue that describing the critique in terms that imply the technique itself is what controls learning interferes with a stance that takes them to be scaffolds for students' own becoming. While we suspect that few critics would explicitly endorse strategies that treat students like objects, the result can still be the same if they do not have ways of understandingand carrying out — critiques in a manner that supports students' personal becoming. We question 
how complete our understanding of the studio ecology can be if we do not have an accurate view of how students take stands (and see themselves taking stands) on choices that critiques present to them. Our efforts to use critiques skillfully, or even to view them clearly, will be hindered because common perspectives of what they are leave both researchers and critics without conceptual resources to see how students might be attempting to use critiques to pursue possibilities that are opened up to them through studio participation.

\section{Method}

To study how students use critiques to press forward into possible forms of the self, we focused on aspects of critiques where students' experiences in doing so were at the forefront. According to Packer (2018), this involves study of how people "represent themselves to themselves and others" (p. 505) as they engage in self-becoming activities. In saying this we do not ignore the importance of also studying social or institutional forces outside of students' control that may impact them in both positive and negative ways. But we do not emphasize those forices here in favor of studying how students depict themselves, as their commentary on how practical activities in which they are involved can be understood. We also recognize that students may be mistaken in how they see themselves or their circumstanes. But, as Packer noted:

Even if we suspect that participants misunderstand what they and others are doing, we still need to take their understanding into account. We do not need to accept [their] understanding ... and our analysis does not need to stop there. But it does need to start there; we should not try to bypass the way participants grasp events and jump directly to claims about what is "really" going on. Indeed, we cannot assert that they are mistaken if we do not in fact know how they understand events. (p. 349; emphasis in original)

So in recognizing that other forces must eventually be taken into account to develop a full picture of students' critique experience, we argue that since these have been the focus of much prior research there is a place for studying students' own depictions to understand how they might take 
up various ways of life - a view that has usually remained hidden when critiques have been studied from other standpoints. We encourage future research to examine how the student voices presented here intersect with other, structural aspects of the studio ecology.

Specifically, we used in-depth interviews to carry out our research. In contrast to methods that attempt to provide a detached observation point, qualitative interviews allowed us to “emphasize ... [the] meaningful human participation" (Yanchar, 2015, p. 107) within students' experiences. They also provided a detailed source of data that could be reported in richness and complexity, and avoid reducing the phenomena we studied to abstract concepts that no longer “give voice" to participants' depictions of themselves or others (Sloan \& Bowe, 2014, p. 1292).

Our goal was not to develop a universal account of how all students press forward into achieving studio possibilities, but to illustrate some ways this could take place, in order to provide an alternative to the perspective that critiques are primarily a pedagogical or socializing technique under the control of instructors and other critics. We hope that by doing so, even those familiar with the issues are encouraged to ask new questions or see situations in fresh ways (Caputo, 2018; Yanchar, 2015).

\section{Participants}

Participants were students enrolled at a university in the United States. Using Brandt et al.'s (2013) framework for identifying studio environments we identified 23 university programs containing at least one studio course. We note that not all programs were from traditional design disciplines; as Boling (2016) recognized, "interest in studio forms of teaching and learning is growing outside the fields of design" (p. 1), which at this university included fields like cybersecurity and law. From the available possibilities we purposefully sampled six: two with historical roots in the studio (graphic design; industrial design); three in which studio teaching is 
a new interest at least at this university (clothing design; information technology; mechanical engineering), and one where the studio is a newly-established pedagogy, using design inquiry to teach a non-design topic (entrepreneurship). One student from each program was purposefully selected as a participant, based on recommendations made by the course instructor (see Table 1). Instructors were given sample criteria to make their recommendation that included whether the student could converse in-depth on topics covered in the interviews, or whether they had unique experiences they could discuss.

Table 1

Summary of Participants

\begin{tabular}{llll}
\hline Pseudonym & Sex & Field & Year in school \\
\hline Beth & Female & Graphic design & Sophomore \\
Joshily & Female & Entrepreneurship & Senior \\
Laurie & Male & Information technology & Senior \\
Matt & Female & Clothing design & Junior \\
Will & Male & Industrial design & Junior \\
\hline
\end{tabular}

\section{Data Gathering}

We interviewed each participant three times and observed them once during a studio class. Interviews ranged from 45-60 minutes and were audio recorded for transcription and analysis. Observations ranged between 25 - 40 minutes and were video recorded to serve as discussion prompts during participants' second interviews. The first interview focused on students background in the class and their general depictions of being critiqued. The second elicited detail about how they depict themselves during critiques by asking them to compare their comments from interview one with activities recorded during our observation (using video 
segments as prompts). The third interview allowed participants to clarify thoughts from earlier discussions, share additional examples, and respond to insights generated from the first two interviews. Each interview started from prepared prompts; based on their responses participants were asked follow-up questions to clarify or elicit examples (see Seidman, 2006). Throughout all interviews we allowed participants to tell their own stories even if this meant an interview protocol was not completed (Brinkmann, 2013).

\section{Data Analysis}

We relied on Packer's (2018) approach for analyzing interviews, that uses the narrative strategies people employ when describing themselves and their practices as the basis for developing an account of how "they are inviting us to view the world we share with them" (p. 149). These narrative artifacts provide clues about "the techniques [people use] for forming [them]selves" as actors in certain forms of life (p. 472), that are not apparent when only analyzing the words they use to describe their experiences. Of course, what people say is also important, but cannot be "extracted" (p. 148) from the strategies they employ when telling their stories. In fact, it is through these strategies that we can see the effects research participants hoped their stories would have on the researcher (and possibly others as well).

Our basic analysis procedure was to organize interview data into a structure that provides insight into how participants' depict critiques and themselves during critiques, using the following phases carried out iteratively throughout our analysis:

- Using Packer's framework for identifying narrative strategies (Packer, 2018, pp. 125-140), we identified sections of individual interview transcripts where participants used a strategy to depict critiques as something, or themselves as something when being critiqued. 
- We summarized each instance using a word or short phrase (usually in the form of a metaphor) that described the depiction being made;

- As we interviewed more participants we refined our initial list by comparing/contrasting individual phrases, looking for relationships between phrases, merging similar phrases, etc.;

- As further interviews were completed, we carried out each of the previous steps again, revising our structure to reflect the additional detail uncovered;

- We allowed each research participant to review our initial insights for their corroboration, and further refined our structure based on their input;

- Using whole/part analysis (Fleming, Gaidys, \& Robb, 2003), we continued to refine our interpretations by considering individual phrases in light of all our data, as well as comparing the whole to the details of our growing structural system.

To facilitate understanding of the depictions our participants offered, we write our report using their words as much as possible. We have made minor adjustments to eliminate phrases that could compromise their anonymity, or to ensure their comments can be understood when being excerpted from the full transcript. The results of our member checks (see below) indicate that they agreed with our adjustments.

\section{Trustworthiness and Limitations}

We helped establish the trustworthiness of our report through the use of reflective memos, negative case analysis, and member checking (Lincoln \& Guba, 1985). We created memos at milestones throughout our process, including after each interview was complete and as we started the data analysis process; these memos provide an audit trail of our activities. We looked for negative cases of the major depictions our analysis generated, by examining 
transcripts to look for plausible counter-interpretations. As relevant, negative cases are included in our report that follows. Finally, we conducted two member checks. First, we shared early insights with participants during their third interviews, allowing them to add detail, and in some cases challenge our interpretations. Second, we provided participants with a draft of our report and asked them to respond to our use of their statements. At most they requested minor changes in how we excerpted their comments, which have been incorporated into our report below.

But even with these efforts we are aware this study does have limitations. First, because of our in-depth interviewing method, our sample is small, and we could not include every field with a studio tradition in our research. While this allowed us to explore in-detail how our participants depict both critiques and themselves, it also necessitates caution, recognizing that students from other fields may depict critiques in different ways. Additionally, because our interview participants were recommended by their instructors there is the possibility they were chosen because they have had generally positive experiences, or are unusually able to reflect on their own experiences. This does not negate the depictions offered by those we did interview, but we do acknowledge that additional research could address gaps in our report and provided other, important accounts of how students' might press forward into studio possibilities. We also recognize our approach can be criticized because our participants could misunderstand how their sense of self is impacted by influences in their broader environment. For this reason we note our report is a starting point for future research that explores how students' depictions intersect with other factors in the studio ecology.

\section{Report of Student Depictions}

Our study was designed to understand how students use critiques to press forward into possible forms of the self, as revealed by how they depict critiques and how they depict 
themselves when being critiqued. We present our report in three parts, each consisting of a matched pair of metaphors that conveys our participants' depictions of critiques and of themselves (see Table 2). At the outset, we emphasize that we can only summarize the richness of experience that participants shared. Given the depth of what each interview contained we cannot produce a comprehensive report; nevertheless, we contend that these metaphors do present an illustrative, if necessarily partial, view of how students depicted pressing into various possibilities of studio life. We also note that the metaphors are not discrete, mutually exclusive categories, and we separate them only for the purpose of analysis and discussion. We encourage readers to notice how they complement each other, and use them together to understand the holistic nature of the experiences our participants were trying to express. Finally, to honor our participants' accounts we first present them without commentary, and leave our analysis of their depictions to later in our discussion.

Table 2

Students' Metaphors, and What They Suggest About Pressing into Studio Possibilities

\begin{tabular}{lll}
\hline Critiques are & Participants are & How students press into possibilities \\
\hline Both signal and noise & $\begin{array}{l}\text { Clear-sighted; able to sift the } \\
\text { relevant out of the irrelevant }\end{array}$ & $\begin{array}{l}\text { Paying attention to those critiques that } \\
\text { align with forms of the self towards } \\
\text { which they feel commitment }\end{array}$ \\
$\begin{array}{l}\text { Window into critics' } \\
\text { trustworthiness }\end{array}$ & $\begin{array}{l}\text { Street-smart; able to learn } \\
\text { lessons about trusting critics } \\
\text { when critiques break down }\end{array}$ & $\begin{array}{l}\text { Learning what kind of critics can } \\
\text { provide them help that is useful and } \\
\text { applicable }\end{array}$ \\
Texts to interpret & $\begin{array}{l}\text { Creative; able to read } \\
\text { between the lines for } \\
\text { subtextual meaning }\end{array}$ & $\begin{array}{l}\text { Being resourceful enough to create } \\
\text { their own knowledge, regardless of } \\
\text { what critics tell them }\end{array}$ \\
\hline
\end{tabular}




\section{Finding Signal in the Noise}

Critiques, according to our participants, are paradoxical, in large part because of their improvised and unrehearsed nature. On the one hand, participants told us critiques often provide relevant, just-in-time support, adapted to precise needs they are currently experiencing. But they also told us that not every critique is useful, as they illustrated through accounts of irrelevant critiques, and their work to distinguish relevant from irrelevant messages. We describe how participants depicted this duality using the metaphor of finding signal in the noise, and their depiction of themselves when doing so as becoming clear-sighted, to highlight the sense of purposeful searching that was evident in how so many of them talked about trying to sift the relevant out of the irrelevant. This was the case even when critiques originated with their instructors. "This is my vision," as Laurie told us, "so I kind of have to pull [my instructor] back to what I want for the project and not what she thinks should happen."

Laurie said this when describing a common form of noise our participants expressed: critiques they see as distractions, pulling them away from what they are trying to accomplish to respond to feedback that, at best, they think is peripheral. Laurie did not attribute this to any bad motives on her instructor's part; rather Laurie talked about her as both knowledgeable and curious, and so could be easily distracted by tangential issues that are appealing but not essential. And while Laurie said the occasional sidetrack can be interesting or even educational, too many threaten to overwhelm her abilities or the time she has available for a project. Yet her depiction of herself when this happens indicates she does not see herself as helpless, but that she is clearsighted enough to determine whether a critique is relevant in helping her accomplish some end, “[I say], wait, I don't want to do that. So what can I do [that is] what I want?" Emily told us something similar. In her case, she said that instructors often tell her personal stories to justify 
their critique of her work, "they kind of go back to those same stories, like, 'this is my experience. Are you solving my experience and the things that I'm challenged by and struggling with?" But she likewise expressed a sense of being clear-sighted, telling us she can avoid such stories becoming distractions, "while I can appreciate the anecdotes in the stories that the professors share, I have to say, like, 'Well, $75 \%$ of the people we've talked to say this is the main problem, so that's what we're going to focus on."”

Of course, our participants also acknowledged many critiques that were ultimately helpful, even if they did not find them to be immediately applicable. But they also talked about other ways critiques could become unreliable noise, such as if critics are not candid in their feedback. Beth provided an example:

People in my class would turn in an assignment that I could tell they had not put really any time into and also that were pretty far from the basic principles that we had learned. And [the instructor] would be critiquing it and trying to justify ways that he felt that it was successful, and it just kind of felt like he was making things up. And the whole class was just kind of like, "Really?" Because it didn't seem that the student had put in effort to actually work on the assignment, or to use the principles that we had learned. So that's frustrating because then you wonder, 'Okay, when you're giving me good feedback, is it really you just trying to make me feel better about my work?' . . . I think it would've been helpful for a lot of students, especially because it was a prereq for applying to the program, and they wanted some feedback of how they could change their work to make it better.

In this case, the noise Beth was sorting through was critiques colored by the instructor's unwillingness (in Beth's words), “to bruise people's egos.” This, seemingly, made it more difficult for her to accept at face value critiques she experienced. But while she did say one answer was for critics to "[give] me good feedback," similar to Laurie and Emily she also described herself in a perceptive, clear-sighted manner, able to determine herself what critiques she should apply, "people are saying really objective things about your work and subjective things. [I have] to interpret what's actually important from this feedback or what's just their 
opinion." At least part of her effort as a studio participant, then, is trying to discern what about a critique might be reliable and worth responding to, and what might be unreliable because it is not sincere, and so is noise she has to filter out before she acts.

We identified a third form of noise as participants described critiques that became less relevant because the circumstances in which they occurred added static that made it difficult for students to see them as accurate evaluations. Josh provided an example. After he and other classmates prepared a project report, their instructor asked to critique their work twenty minutes before a scheduled presentation to their client. This introduced noise because the instructor was rushed, and Josh thought much of his feedback was hasty and ill-considered, "I think he was coming in quick to correct .... [but] again and again we said, 'well, that's being covered in the next slide,' or, 'we've talked about that three slides previously.' And that became frustrating really quickly." Also, given the timing, Josh suggested that further noise was introduced in the form of critique-induced anxiety, "[it] came too late. It was kind of like, we've already finished this, and you're saying re-write a whole bunch of stuff and we don't have time to do that. So now I feel more unsure about the presentation."

In contrast to the comments of Beth, Laurie, and Emily, Josh did not tell us that he found a relevant message by sifting through the irrelevant. Rather, he suggested his instructor should have handled the entire situation different if students were to find any hoped-for relevance in it, "[I wish] he had taken notes for us [during the presentation] and said, 'here's some things I would do differently next time,' instead of, 'hurry and change these things before you talk to the client!' [Laughter]" Yet even though the substance of his response differed, Josh still seemed to be depicting himself as a clear-sighted studio participant. He indicated that the large number of corrections and the uncertainty he felt at the time were noise that, upon reflection, he was able to 
see through, and that his new assessment of the presentation was not as grim as his instructor's response initially implied. So he was comfortable in largely disregarding the critique as an unreliable evaluation of his (and his fellow students') work.

In these depictions of themselves as clear-sighted we see an aspect of how participants to use critiques to press forward into possible forms of the self. In their own ways, Laurie, Beth, Emily, and Josh all depicted themselves as having learned to monitor their own progress, telling us they were capable of recognizing when, and to what extent, a critique was a relevant signal that could help them pursue what they wanted. They did not depict critiques as channeling their efforts so as to achieve some critic's desired outcomes, but rather represented themselves as being able to direct their studio achievements because they can discern what is in their own interest at least as much as do those who critique them. While this, alone, cannot fully account for how students might use critiques to press forward into forms of the self, we argue that it is an important step. It illustrates how they might try to see what particular critiques (out of the many they experience) will actually be useful for them to apply, and suggests that they see themselves as being able to take stands on their own becoming by primarily paying attention to critiques that align closely with forms of the self towards which they feel a commitment.

\section{Learning Who They Can Trust}

Some participants talked about how critiques can reveal whether, or under what circumstances, critics can be relied upon. To describe this we use the metaphor of critiques being a window into the trustworthiness of critics, with participants becoming street-smart as they learn practical lessons about trusting critics. While none of our participants told us about critiques that were so problematic they completely removed themselves from a relationship, some described events that damaged their trust enough that they are reluctant to take feedback from their 
perceived offender again. We illustrate this through an extended example from Matt. As he explained, "we had, as a group, worked all semester with this company. And both the company and our professor had said all along, 'okay, it looks like it's going well. Keep working."” But during the end-of-semester presentation, the client rejected the product that Matt and his group delivered. When they asked why, the client told them that they "didn't correctly identify the brand values," and so their work had actually been "wrong from the beginning." Matt continued, "[but] we were following these values [because] they had said, 'yes, you're right. These are good.' Then we're like, 'okay, we can move onto the next stage, where we base everything off of those values." Yet, regardless of the understanding Matt's group thought they had, in the end they were told they should have taken a very different direction.

While the client's reaction hurt, Matt said he expected such things would occasionally happen throughout his career. But he reacted differently to his instructor's response, seeing in it evidence this particular instructor was not trustworthy. Matt described how, even though the instructor had encouraged his group to pursue the course they had taken, during the final critique, “[he] kind of just looked away and wasn't even willing to address the situation.” They later asked him what happened, and his response was, "well, I thought you knew what you were doing." In reflecting on this Matt said:

It felt like he had opportunities to intervene [earlier in the project] and he chose not to give his help, or his expertise even.... And that's why it was hard, because there's an expectation, like, you're supposed to step in. If we go off, really far off, you are supposed to help us. Kind of shepherd us back in a little bit. And it was hard because it felt like he let us down.

Even months after the experience Matt still found it upsetting, in large part because his instructor had broken the social contract that was foundational to their relationship, "the reason we're doing school first is so there are these teaching moments of, 'I'm going to intervene now because 
you're a student and I'm going to teach you something."” Matt asserted the instructor

"blindsided" him, violating the "sense of trust" he thought existed between them, "I was listening to you, and you didn't say anything! You kind of broke that trust."

As he concluded his account, Matt described how this experience helped instill a sense of being street-smart in how he participated in future critiques. He explained there was a "shift in expectations for me," because "there wasn't a fulfillment of what he [the instructor] was supposed to be doing." He insisted the experience was not a temporary breakdown but revealed an aspect of his instructor's character, "now I know something about him. I know this is how he works." And Matt anticipated it will have an effect on how he acts if he has to work with this instructor again, "[now] I'm going to be able to adjust my work accordingly." In taking this stance, Matt seemed to be saying that he learned a practical lesson: he will make judgments about how to present his work, or otherwise act around the instructor, to care for his own interests because he does not see this person as being willing to do so. While Matt thinks his instructor is a skilled designer, and is willing to admit there is much about him worth respecting, he is reluctant to actually accept critiques from this instructor again, “I don't know if I'll trust that professor much anymore, just because it hurt." In telling us this, Matt emphasized that he will be more cautious in how he listens to, and applies, critiques in the future.

Not every example we heard was this extreme, with other participants telling us that even minor breakdowns could be reveal how much they can trust their critics. For instance, Josh told us how he was less willing to trust critics who seemed disengaged during critiques:

I think a person's enthusiasm . . . definitely affects how much you trust their feedback and how much you want feedback from them. If [instructors] just kind of roll in nonchalant, it's hard to feel excited about what [they're] doing, and hard to feel like you can really trust whatever their feedback is. 
Will described a different type of breakdown in trust, focused less on character and more on ability. As he reflected on critiques offered by an inexperienced instructor, he said, "I don't think he had fully thought out what he wanted. . . . [When he critiqued] I didn't feel any expectations, I didn't feel it mattered. . . . And I honestly felt like, whatever, I'm just going to move on.” Beth also noted how her perceptions of instructors' experience affects her trust in them, as seen in the account related earlier of her instructor who seemed unwilling to give candid feedback. How Beth talked about this individual suggested she trusted him less since she was uncertain whether she could take what he said at face-value. This was not only because she thought he was "just trying to make me feel better about my work," but also because she wondered, "maybe [he was] unsure as to why he actually did like or dislike certain things."

Further, in describing these experiences Josh, Will, and Beth also seemed to express a sense of themselves as being savvy, street-smart studio participants, who have learned practical lessons about trusting critics. For example, Josh now relies on a rule of thumb he learned when facing unenthusiastic critics, “just kind of subconsciously I don’t trust [instructors] as much . . . [if] it appears as though [they] don't care about this class as much as they do [their] other classes." Will summarized the lesson he took away from his inexperienced critic, "if you have a big question, it's harder for the [new] professor to answer it." And Beth shared a lesson about coping with critics who have a tendency to give unreliable feedback, "I always present the choices I'm making, explaining all of my ideas behind it so [critics] don't really have a choice of just giving me one flat answer."

In participants' depictions of themselves as street-smart we see an extension of their earlier depiction of themselves as clear-sighted. When they told us about what they do when critiques break down we saw them describing wisdom they have learned about how to participate 
in critiques in a manner that cares for their personal becoming. We note their lessons were not to completely disregard critics' advice, but rather were about how to recognize when that advice is most useful, or how to approach critique situations to maximize the chance they would learn something worthwhile. They did not depict being street-smart as being wholly independent of others, but that they needed to be wise enough to recognize that others are not always willing or able to assist them in ways that they need. This presents a more complete picture of how participants use critiques to press forward into possible forms of the self. Not only did they depict themselves as taking stands on studio possibilities by paying attention to critiques that align with the forms of self towards which they feel committed, but they also say they are capable of learning what kinds of critics are likely to provide them help that might be useful and applicable.

\section{Reading Between the Lines}

Critiques carry multiple meanings for our participants. At a basic level they talked about them as a straightforward evaluation of their work or skills, and as such they described the process of interpreting their critics' intent as being relatively unambiguous. But in addition to this, participants also recounted how they often try to abstract other principles out of critiques, that go beyond the explicit instructions being provided. Matt offered an example. After hearing another student being critiqued for only developing one persona as part of her project analysis, Matt explained that even though it was not directed towards him, he still learned a lesson:

A persona is there to help you as a designer to create as many and the best ideas that you can. So what [our instructor is] saying is, "at this point in the project you don't need to be narrowing in on a finished [product]. You still have the timeline to come up with more ideas." . . . His goal is to say, "I want you to go create all these other ideas," again, with the objective to find something new. 
None of these insights were made explicit by Matt's instructor; the actual words spoken were only directions to develop more than one persona. But we see no reason to doubt the lesson Matt described. Having observed this instructor as he interacted with Matt's class we can imagine him endorsing the message even if he did not have it specifically in mind at the time. Yet the accuracy of Matt's interpretation is less important than the fact he was interpreting, taking the specific critique he heard and trying to draw out of it an additional lesson he could use. To describe this depiction of critiques as having meaning beyond a specific evaluation, we use the metaphor of texts to interpret, with participants depictions of themselves as being creative as they read between the lines for subtextual concepts or ideas.

In Matt's case the line he drew between the critique and the lesson learned was clear, meaning his instructor was trying to make a certain point and that point was at least closely related to the meaning Matt extracted. But we noted other cases where participants described lessons that were not directly related to the explicit evaluation that critics provided. Examining these provides further evidence that their reading between the lines is a creative act in the sense that they generated ideas they found both novel and useful (see Beghetto \& Kaufman, 2014). Laurie reflected on one such lesson, prompted by her observation that instructors' sometimes only offer superficial critiques. Having received numerous critiques like this, Laurie reflected that her critics' lack of attention might mean she does not need to be so self-critical of her own work, "when people look at my clothes . . . they're not staring and looking for imperfections. So that's kind of what I keep in mind." Will, however, read these kind of situations in a different way, finding in the critics' lack of attention a lesson about what kind of student he should be, "If you know how to ask the question, anyone can answer it. . . . [So] I should probably be more proactive and ask for the missing steps." In both instances it is the interpretive activity we draw 
attention to, not the specific lessons our participants said they learned. In reading between the lines these students seemed to be actively searching for meaning, finding subtext in their interactions with critics that were likely unintended, but still (for the students) significant.

This view of our participants' depictions seems to be strengthened when we consider a case where a student's reading between the lines was, in a sense, in tension with instructions a critic provided. Emily described an instructor who consistently critiqued her and her team for not spending enough time refining their business plan. He wanted them to stop working on their technical platform and devote their efforts towards improving their plan instead. Emily strongly disagreed with this position, in part because she did not think her instructor had the experience he needed to see how developed their plan was, and in part because she was feeling pressure from potential customers to show them something tangible. But rather than negotiating with her instructor, or, on the other hand, ignoring him, Emily told us she applied a creative strategy that would allow her to both apply the instructor's critique while spending most of her time on what she thought was most important, "I take the feedback and find a way [to look at it] so it could help our team." In this instance, she organized her team to divide-and-conquer, "we have six members of our team. We can have two members do [the business plan] and [the rest] really focused on the technical."

In using this example we do not criticize Emily's response; as instructors ourselves we wish more students were as confident in taking charge of their own education, and we can imagine that Emily's instructor might have endorsed her actions if she told him about her plans. But we note that Emily did not simply disregard the critique in favor of what she already wanted to do. Instead, she found a way of reading the critique that would both satisfy her instructor's request as well as satisfy her views of what she needed to work on most. As she did this we see 
her seemingly depicting the situation as if it were meant to be interpreted, and if she were creative enough she could find a meaning that would allow her to satisfy both conditions she was trying to fulfill. We repeat what we quoted a moment ago, "I take the feedback and find a way [to look at it] so it could help our team." And so while we contend that the metaphor of texts to interpret does express how Emily depicted this critique she experienced, we also clarify that her creative reading does not appear to be solely driven by a desire to find messages her instructor may have hidden. While an instructor-centric view of what messages a critique contains may explain how Matt depicted the lesson he learned, in Emily's case (and to a lesser extent Laurie's and Will's), we see the possibility that the key to decoding a critique can be students' interests and needs as well. The explicit critique provided Emily a starting point, and perhaps some constraints to work within. But, using another metaphor, her interpretation appeared more like eisegesis than exegesis, as she creatively reworked the critique into advice that, in her judgement, was more useful for the problem she was trying to solve.

In this summary of our participants as creative readers we complete our picture of how their depictions reveals something about how they use their critiques to press forward into possible forms of the self. As they depicted themselves as interpreting messages found within critiques, we saw them saying that they can be resourceful enough to create applicable knowledge, regardless of what their critics actually tell them (or, in some cases, did not tell them). Matt, Laurie, Will, and Emily all respected critiques in the sense that they assumed they could learn something valuable from what their critics had to say. But they also told us the meanings of those critiques were something they determined; the explicit comments of critics provided a starting point, but the usefulness of the messages was something participants told us that they created themselves. 


\section{Discussion}

While our participants' depictions are only some of the ways students might press into the possibilities of studio life, they can still be useful in developing a picture of critiques that contrasts with a view of them as being primarily a strategy for managing studio outcomes. In framing critiques in this way we do not want to give the impression that we see no value in critics' actions, or that critics have no role in students' education. As we mentioned at the outset, one of our interests in studying this issue was to help critics learn from students' experiences, so they can better support students during critique. So we affirm the value of the assistance critics can provide — as did the participants in our study. And we clarify that when we report how participants depicted themselves in such an active manner, we are not arguing for them to be left alone to develop identities without assistance. We recognize that, in contrast to their depictions, sometimes students do not know what is in their interest, misunderstand whether or not a critic can help them, or their attempts to create useful knowledge may be lacking without the help of those more knowledgeable and skillful than themselves. So we argue that students' depictions should be taken into account because they reveal something about critiques that, if ignored, could have a negative impact on the student experience, but that these depictions themselves do not directly translate into new methods for carrying out critique. We seek to use our report to inform readers' experience, not prescribe what they should do.

As we conclude, then, we explore how the depictions we reported can be useful for framing critiques in a manner that supports students' personal becoming. The core of our argument is that instructors/critics can support students as they press into studio possibilities by: (a) exercising pedagogical humility; and (b) remaining open to true surprise when making judgments about when or how to critique. We discuss each of these in turn. As relevant, 
throughout our discussion we cite related philosophical and theoretical literature to clarify and extend our argument.

\section{Exercising Pedagogical Humility}

Our report implies that critics should bring a sense of pedagogical humility to the task of offering critiques. Even the most overbearing critic should pause when reminded that, despite any outward response, students are not passively absorbing the critic's directives. They might be changing the messages critics intend (as did Emily), possibly ignoring them (Will), becoming skeptical about them (Matt), or perhaps responding in manners we did not see in our study (such as becoming overly competitive or protective of their ideas; see Gray \& Smith, 2016). This is consistent with Gray's (2013b) observation that the habitus of the studio, that supports the negotiation of students' design identity, is a co-constructed phenomenon, weaved together both by the "environment" and "students' personal assumptions or beliefs about critique" (p. 203).

Yet, as researchers have also observed, when critics see students exhibiting a sense of independence their response might be to assert their authority in an attempt to secure those students' compliance (Webster, 2007). But we argue that even if critics have the institutional authority to prevail in such struggles, this does not put an end to students attempting to press into various possibilities they see, although clearly it could change the types of possibilities that are open to them in-the-moment. For instance, although none of our participants described cases as extreme as those studied by Webster, we see some similarities in Matt's account of losing trust in his instructor. Although the instructor had enough temporary control to deflect Matt's inquiry into what happened, the lesson Matt learned about trusting critics has become a disposition he carries forward into future critiques, and that his instructor has limited ability to influence. 
A practical way critics might express pedagogical humility could be to actively soften the typical power structures in the studio that enable their control. We are not the first to suggest the power dynamics of critiques should change to make them a more productive and humane experience (cf. Anthony, 1991; Gray \& Smith, 2016; Webster, 2007). And we are also not arguing that critiques should be lenient, avoid addressing issues directly and clearly, or never deliver messages that students find hard to hear. But we do suggest that critics' abilities to intervene appropriately and successfully may be improved as their overall critique approach minimizes the differences in power between them and their students (although we recognize that it will never be eliminated). For instance, critics might actively solicit what students want out of a critique before offering suggestions of their own. This could draw out the effects of students' attributes such as clear-sightedness, street-smarts, and creativity, giving them a chance to express what critique might be most helpful, or the type of knowledge they are looking to create. Even when students' actual abilities to determine these things may be limited, whatever they express can still be a virtue, since even when they do not have the experience to make the best decisions their future ways of life will be much more impacted by a critique than the critic's future will be. Consequently, students can bring a sense of investment into a critique that the critic simply does not have. As Laurie reminded, her projects are "my vision, so I kind of have to pull [my instructor] back to what I want for the project and not what she thinks should happen."

We argue that through their greater investment, students may discern aspects of a problem, project, or situation their critics do not, and so generate possibilities for responding that critics similarly cannot see. In this regard we consider again Emily's idea for breaking up her team to work on both their business plan and technical platform. While we cannot definitively conclude that this was better than her instructor's idea to only work on the business plan, Emily's 
response did seem to be shaped by all the influences her team was facing while the instructor seemed to have a more detached and partial perspective. But even if in his experience the instructor could see something in Emily's idea that indicated a flaw in her reasoning, her stronger sense of the personal stakes is weighty enough of a factor that he should be willing to take her seriously, and engage in true dialogue before recommending a course of action.

Our recommendation holds even in cases where students may not be as capable or intentionally reflective as Emily, or pursuing courses of action the instructor finds to be selfish, unskillful, or unprofessional (in the language of our study, cases where good evidence indicates a student is not being clear-sighted, street-smart, or creative). Here an instructor may rightly have an obligation to offer even sharp critiques. But the spirit of pedagogical humility we recommend still suggests that in these cases instructors likewise recognize their detached vantage point when compared to their students, and that whatever forms of the self that students express are a type of commentary they are offering about how they see the situation (Dreyfus, 1991; Taylor, 1985). By engaging in dialogue with these students, then, instructors are likely to better understand the scope of the situation students that believe they are in, and so any critiques those instructors offer are correspondingly more likely to be relevant to the students in some fashion. We suggest this is the case even where students' views are obscured or limited in significant ways.

We emphasize, however, the importance of critics really giving themselves over to the mood of pedagogical humility, and not only employing techniques that mimic it regardless of what they feel. As Josh's account of recognizing his critic's disengagement should highlight, students are likely to discern what critics are really feeling, and respond to the mood they see and not the technique being used. Additionally, as Dreyfus (1991) argued, unless one sincerely experiences a mood, one is not able to relate to the world in a manner truly suggestive of that 
mood. So it may be that unless critics actually feel pedagogical humility they will be unable to fully help students explore their ideas in the manner that we suggest is available to them through this mood. While there is little that can be done to force this for instructors who are uninterested, the institutional culture of studio programs can encourage it by rewarding the pursuit of goods consistent with pedagogical humility, as we have encouraged elsewhere (McDonald \& Michela, 2019). They could also formally recognize instances of pedagogical humility, perhaps providing examples of its manifestation in practice, or by sponsoring more focused research on the topic.

\section{Remaining Open to True Surprise}

Our observation that students use critiques to pursue the possibilities of studio participation means that the outcomes of critiques (positive or negative) cannot be truly predicted in advance, since critics cannot fully take into account how students will use a critique to pursue what they see opened up to them. This is the case even when considering the strength of social norms or other artifacts of enculturation that have been shown to influence patterns of student response during critique (Gray, 2013b). While such norms may certainly open or close various possibilities for students, they are not controlling forces, and students may (and often do) press into them in unique ways (Sugarman, 2005). Consider, for example, how our participants used their prior experiences to construct lessons about what kind of critics they can trust. Those lessons will affect how they respond to critics they encounter in the future, with their actions taking critiques in directions the critics may not be able to anticipate. This suggests that critics should be open to true surprise during critiques, and not avoid it because they are set on a course of action they prejudge to be best.

It may also be, however, that critics are not avoiding surprise but simply do not see it. To consider this possibility we start with a response that critics might make to the notion of being 
surprised: of course students could present something unexpected, but experienced critics are not surprised by this. Students' responses are not random, and even when a critic sees something new she can become quite skillful in recognizing what certain students are likely to do in various interactions. Yet, as Dreyfus $(2014,2017)$ argued, this is not a matter of critics predicting students' behavior, which implies they are using a set of rules or heuristics to forecast what is likely to occur. The number of possible rules in a given situation is so overwhelmingly large that people cannot master a strategy of applying the correct the rules. Rather, expert critics recognize the particularities of the situation — what makes this student an individual and not an example of the general - and extemporaneously respond as they did the last time they saw someone similar.

The difference lies in this: in the first case, critics are trying to eliminate surprise by looking for what about the situation is general so they can find an applicable rule to apply; so the more they can minimize surprise, the more they think they can predict the outcomes of using the right rule. But in the second case, critics have refined their ability to see. Like a skilled musician who can hear subtle differences in tone better than can the casual listener, a skilled critic can discriminate what makes a certain critique distinct when compared to others, and then sensitively respond to the uniqueness they see. If critics prejudge a moment as merely being another example of the general, they will likely miss the very aspects of the situation in which students' pressing into different possibilities may be found. This is where surprise can still be manifest, regardless of the critic's prior experience. If they give themselves over to being surprised, their world will present itself as surprising and they will better see the unexpected elements in it (Dreyfus, 1991), and so, hopefully, be better prepared to assist students in the particular needs being expressed and explored. While our same caution about forcing surprise applies here as in our discussion of moods earlier, we also note that researchers or program administrators can help 
instructors refine their ability to recognize surprising characteristics of a situation by encouraging them to reflect on numerous examples of critiques, especially those that may only differ in fine details (Dreyfus, 2014). Instructors themselves can also help each other by sharing stories of critiques they offer, along with how students responded to the feedback.

Additionally, remaining open to surprise by attending to the particularities of a situation implies that the various strategies that have been developed for offering critiques could have limited applicability, because by their nature they are meant to respond to situational generalities rather than particularities. Thus, being open to surprise has a practical consequence:

instructors/critics may find themselves relying more on how students disclose themselves in the moment rather than applying discrete techniques. Strategies for offering critiques may be important for new critics to get a sense of situations they encounter, or to understand what kind of actions are generally expected of them. But as their expertise grows they will need to be willing to move beyond explicit techniques or rules in favor of responding to what they see in the individual instance (Dunne, 1997). To clarify, we consider again the case of Josh's instructor insisting on a critique before an important presentation. While in the abstract it is easy to justify such an action (based on a principle like: evaluate students' work before high stakes situations), is it possible that if the instructor had been more attuned to what Josh was experiencing that he would have considered another option? While our report is only based on Josh's depiction of the situation, we at least speculate that if other students reacted as did he (disregarding much of the advice), then the critique did not have the desired effect of helping students improve, regardless of how reasonable an idea it seemed in advance.

Yet ultimately our purpose is not to recommend that critics follow this specific advice, either. Our point is that there is no infallible response that can be specified beforehand, and 
attempts to evaluate a situation from a perspective that attempts to minimize surprise will only be of limited applicability. While this includes our assessment here, it must also be recognized that it includes the assessment of anyone attempting to provide principles or heuristics to help instructors/critics improve. Strategy and technique have their place. But the best support critics can provide will ultimately be to "stay open and involved and draw on his or her past experience" (Dreyfus, 2017, p. 35) as they see students pursuing various possibilities in each, current moment, to make decisions about what assistance they can appropriately offer.

\section{Closing Thoughts}

In this paper we studied how students use critiques to press forward into possible forms of the self, as revealed by how they depict critiques and how they depict themselves when being critiqued. We have described how our participants depicted critiques as (a) signal in the noise; (b) a window into critics' character; and (c) texts meant to be interpreted. Likewise, we described their depictions of themselves as being (a) clear-sighted (able to sift relevant out of irrelevant critiques); (b) street-smart (able to learn lessons about trusting critics when critiques break down); and (c) creative (able to read between the lines of critiques to find subtextual meaning). In our discussion of these depictions we illustrated how they help frame critiques in ways that facilitate, rather than interfere with, students' practice of using them to care for their personal becoming. In doing this we focused on (a) exercising pedagogical humility; and (b) remaining open to true surprise when making judgments about when or how to critique. Although work remains to compare our report with other studies of critique practice (both to improve our report and to consider how it might illuminate other scholarship), we suspect that our discussion will sound familiar to many readers. And based on our work with a number of studio instructors we 
likewise suspect that the kinds of stances we recommend may already be a part of many studio cultures.

So we reiterate that our intent has not been to propose wholly unprecedented ideas about how critiques can take place. Rather, as we stated at the outset, our aim was to develop a way of speaking about critiques that considers their foremost purpose to be supporting students who are

pressing into forms of the self that are opened up through studio participation. We offer this as an alternative to a view of critiques as primarily being a pedagogical or socializing technique under the control of instructors and other critics. And so while we would be pleased if readers find our ideas novel, our first hope is that this study provides scholarly insights into relationships with students that they might already have, or may hope to have but did not have language to conceptualize in a concrete enough manner to actually carry out. Through students' depictions of critiques and of themselves, a way of viewing the studio ecology is opened up that clarifies how they might be attempting to use critiques to press forward into new forms of the self. And so we conclude by arguing that if instructors/critics align their critique efforts so they support what students are simultaneously doing, they can find themselves better cooperating with students in the ultimate achievement of those same ends.

\section{Compliance with Ethical Standards}

Ethical approval: All procedures performed in studies involving human participants were in accordance with the ethical standards of the institutional and/or national research committee and with the 1964 Helsinki declaration and its later amendments or comparable ethical standards.

Informed consent: Informed consent was obtained from all individual participants included in the study. 


\section{References}

Anthony, K. H. (1991). Design juries on trial: The renaissance of the design studio. New York, NY: Van Nostrand Reinhold.

Beghetto, R. A., \& Kaufman, J. C. (2014). Classroom contexts for creativity. High Ability Studies, 25(1), 53-69. https://doi.org/10.1080/13598139.2014.905247

Belluigi, D. Z. (2016). Constructions of roles in studio teaching and learning. International Journal of Art and Design Education, 35(1), 21-35. https://doi.org/10.1111/jade.12042

Boling, E. (2016). Introduction. In E. Boling, R. A. Schwier, C. M. Gray, K. M. Smith, \& K. Campbell (Eds.), Studio teaching in higher education: Selected design cases (pp. 1-3). New York, NY: Routledge.

Brandt, C. B., Cennamo, K., Douglas, S., Vernon, M., McGrath, M., \& Reimer, Y. (2013). A theoretical framework for the studio as a learning environment. International Journal of Technology and Design Education, 23, 329-348.

Brinkmann, S. (2013). Conversations as research: philosophies of the interview. In B. Dennis, L. Carspecken, \& P. F. Carspecken (Eds.), Qualitative research: A reader in philosophy, core concepts, and practices (pp. 149-167). New York, NY: Peter Lang Publishing, Inc.

Budge, K. (2016). Learning to be: The modelling of art and design practice in university art and design teaching. The International Journal of Art \& Design Education, 35(2), 243-258. https://doi.org/10.1111/jade.12060

Caputo, J. D. (2018). Hermeneutics: Facts and interpretation in the age of information. London, UK: Pelican Books.

Cardella, M. E., Buzzanell, P., Cummings, A., Tolbert, D., \& Zoltowski, C. B. (2014). A tale of two design contexts: Quantitative and qualitative explorations of student-instructor 
interactions amidst ambiguity. Design Thinking Research Symposium. West Lafayette, IN: Purdue University.

Cennamo, K., \& Brandt, C. (2012). The "right kind of telling": Knowledge building in the academic design studio. Educational Technology Research and Development, 60(5), 839858.

Cossentino, J. (2002). Importing artistry: Further lessons from the design studio. Reflective Practice, 3(1), 39-52. https://doi.org/10.1080/14623940220129861

Crysler, C. G. (1995). Critical pedagogy and architectural education. Journal of Architectural Education, 48(4), 208-217.

Dannels, D. P., Gaffney, A. H., \& Martin, K. N. (2008). Beyond content, deeper than delivery: What critique feedback reveals about communication expectations in design education. International Journal for the Scholarship of Teaching and Learning, 2(2), 1-16. https://doi.org/10.20429/ijsotl.2008.020212

Dannels, D. P., \& Martin, K. N. (2008). A genre analysis of feedback across novice to expert design studios. Journal of Business and Technical Communication, 22(2), 135-159. https://doi.org/10.1177/1050651907311923

Dreyfus, H. L. (1991). Being-in-the-world: A commentary on Heidegger's Being and Time, Division I. Cambridge, MA: The MIT Press.

Dreyfus, H. L. (2014). Skillful coping: Essays on the phenomenology of everyday perception and action (M. A. Wrathall, ed.). Oxford, UK: Oxford University Press.

Dreyfus, H. L. (2017). Background practices: Essays on the understanding of being (M. A. Wrathall, ed.). New York, NY: Oxford University Press.

Dunne, J. (1997). Back to the rough ground: Practical judgment and the lure of technique. Notre 
Dame, IN: University of Notre Dame Press.

Dutton, T. A. (1991). The hidden curriculum and the design studio: Toward a critical studio pedagogy. In T. A. Dutton (Ed.), Voices in architectural education: Cultural politics and pedagogy (pp. 165-194). New York, NY: Praeger.

Fleming, V., Gaidys, U., \& Robb, Y. (2003). Hermeneutic research in nursing: Developing a Gadamerian-based research method. Nursing Inquiry, 10(2), 113-120.

Gray, C. M. (2013a). Discursive structures of informal critique in an HCI design studio. Nordic Design Research Conference 2013, 110-118. Copenhagen, Denmark.

Gray, C. M. (2013b). Informal peer critique and the negotiation of habitus in a design studio. Art, Design \& Communication in Higher Education, 22(2), 195-209. https://doi.org/10.1386/adch.12.2.195_1

Gray, C. M. (2014). Living in two worlds: A critical ethnography of academic and protoprofessional interactions in a human-computer interaction design studio. Indiana University, Bloomington, IN.

Gray, C. M., \& Smith, K. M. (2016). Critical views of studio. In E. Boling, R. A. Schwier, C. M. Gray, K. M. Smith, \& K. Campbell (Eds.), Studio teaching in higher education: Selected design cases (pp. 260-270). New York, NY: Routledge.

Guignon, C. (2012). Becoming a person: Hermeneutic phenomenology’s contribution. New Ideas in Psychology, 30(1), 97-106.

Gur, B. S., \& Wiley, D. A. (2007). Instructional technology and objectification. Canadian Journal of Learning and Technology, 33(3).

Hokanson, B. (2012). The design critique as a model for distributed learning. In L. Moller \& J. Huett (Eds.), The next generation of distance education: Unconstrained learning (pp. 71- 
83). New York: Springer-Verlag.

Koch, A., Schwennsen, K., Dutton, T. A., \& Smith, D. (2002). The redesign of studio culture. Washington, DC: American Institute of Architecture Students.

Lawson, B., \& Dorst, K. (2009). Design expertise. Burlington, MA: Elsevier Ltd.

Ledewitz, S. (1985). Models of design in studio education. Journal of Architectural Education, $38(2), 2-8$.

Lincoln, Y. S., \& Guba, E. G. (1985). Naturalistic inquiry. Newbury Park, CA: Sage Publications.

Matthews, M. T., \& Yanchar, S. C. (2018). Instructional design as manipulation of, or cooperation with, learners? TechTrends, 62(2), 152-157. https://doi.org/10.1007/s11528017-0245-6

McDonald, J. K., \& Gibbons, A. S. (2009). Technology I, II, and III: Criteria for understanding and improving the practice of instructional technology. Educational Technology Research and Development, 57(3), 377-392.

McDonald, J. K., \& Michela, E. (2019). The design critique and the moral goods of studio pedagogy. Design Studies, 62, 1-35. https://doi.org/10.1016/j.destud.2019.02.001

Morton, J., \& O’Brien, D. (2005). Selling your design: Oral communication pedagogy in design education. Communication Education, 54(1), 6-19. https://doi.org/10.1080/03634520500076885

Nelson, H. G., \& Stolterman, E. (2012). The design way: Intentional change in an unpredictable world (2nd ed.). Cambridge, MA: The MIT Press.

Nixon, J. (2017). Hans-Georg Gadamer: The hermeneutical imagination. New York, NY: Springer. 
Oak, A. (2000). It's a nice idea, but it's not actually real: Assessing the objects and activities of design. Journal of Art and Design Education, 19(1), 86-95. https://doi.org/10.1111/14685949.00205

Oak, A., \& Lloyd, P. (2016). 'Throw one out that's problematic': Performing authority and affiliation in design education. CoDesign, 12(1-2), 55-72. https://doi.org/10.1080/15710882.2015.1110179

Oh, Y., Ishizaki, S., Gross, M. D., \& Do, E. Y.-L. (2013). A theoretical framework of design critiquing in architecture studios. Design Studies, 34(3), 302-325. https://doi.org/10.1016/j.destud.2012.08.004

Osguthorpe, R. T., \& Osguthorpe, R. D. (2007). Instructional design as a living practice: Toward a conscience of craft. Educational Technology, 47(4), 13-23.

Packer, M. (2018). The science of qualitative research (2nd ed.). New York, NY: Cambridge University Press.

Patton, P. (1989). Taylor and Foucault on power and freedom. Political Studies, 37(2), 260-276. https://doi.org/10.1111/j.1467-9248.1989.tb01482.x

Percy, C. (2004). Critical absence versus critical engagement: Problematics of the crit in design learning and teaching. Art, Design \& Communication in Higher Education, 2(3), 143-154.

Polt, R. (1999). Heidegger: An introduction. Ithaca, NY: Cornell University Press.

Rychlak, J. F. (1991). Artificial intelligence and human reason: A teleological critique. New York, NY: Columbia University Press.

Scagnetti, G. (2017). A dialogical model for studio critiques in design education. The Design Journal, 20(sup1), S781-S791. https://doi.org/10.1080/14606925.2017.1353024

Schrand, T., \& Eliason, J. (2012). Feedback practices and signature pedagogies: What can the 
liberal arts learn from the design critique? Teaching in Higher Education, 17(1), 51-62. https://doi.org/10.1080/13562517.2011.590977

Seidman, R. (2006). Interviewing as qualitative research (3rd ed.). New York, NY: Teachers College Press.

Slife, B. D., \& Williams, R. N. (1995). What's behind the research: Discovering hidden assumptions in the behavioral sciences. Thousand Oaks, CA: SAGE Publications, Inc.

Sloan, A., \& Bowe, B. (2014). Phenomenology and hermeneutic phenomenology: The philosophy, the methodologies, and using hermeneutic phenomenology to investigate lecturers' experiences of curriculum design. Quality \& Quantity, 48, 1291-1303. https://doi.org/10.1007/s11135-013-9835-3

Sugarman, J. (2005). Persons and moral agency. Theory \& Psychology, 15(6), 793-811. https://doi.org/10.1177/0959354305059333

Taylor, C. (1985). Human agency and language: Philosophical papers (Vol. 1). https://doi.org/10.1017/CBO9781139173483

Tracey, M. W., \& Hutchinson, A. (2016). Uncertainty, reflection, and designer identity development. Design Studies, 42, 86-109. https://doi.org/10.1016/j.destud.2015.10.004

Uluoğlu, B. (2000). Design knowledge communicated in studio critiques. Design Studies, 21(1), 33-58. https://doi.org/10.1016/S0142-694X(99)00002-2

Webster, H. (2006). A Foucauldian look at the design jury. Art, Design \& Communication in Higher Education, 5(1), 5-19. https://doi.org/10.1386/adch.5.1.5/1

Webster, H. (2007). The analytics of power: Re-presenting the design jury. Journal of Architectural Education, 60(3), 21-27. https://doi.org/10.1111/j.1531-314X.2007.00092.x Willenbrock, L. (1991). An undergraduate voice in architectural education. In T. A. Dutton 
(Ed.), Voices in architectural education: Cultural politics and pedagogy (pp. 97-119). New York, NY: Praeger.

Williams, R. N. (1987). Can cognitive psychology offer a meaningful account of meaningful human behavior? The Journal of Mind and Behavior, 8(2), 209-222.

Yanchar, S. C. (2015). Truth and disclosure in qualitative research: Implications of hermeneutic realism. Qualitative Research in Psychology, 12(2), 107-124. https://doi.org/10.1080/14780887.2014.933460

Yanchar, S. C. (2016). Identity, interpretation, and the moral ecology of learning. Theory \& Psychology, 26(4), 496-515. https://doi.org/10.1177/0959354316651940

Yanchar, S. C., Spackman, J. S., \& Faulconer, J. E. (2013). Learning as embodied familiarization. Journal of Theoretical and Philosophical Psychology, 33(4), 216-232. 